Case Report

\title{
Extensive Presentation of Central Ossifying Fibroma Treated with Conservative Surgical Excision
}

\author{
Matheus Henrique Lopes Dominguete, ${ }^{1}$ Alexandre Augusto Sarto Dominguette, ${ }^{1}$ \\ Bruno Henrique Matos, ${ }^{1}$ Paulo Roberto Dominguete, ${ }^{1}$ \\ Jorge Esquiche León, ${ }^{2}$ and Lucinei Roberto Oliveira ${ }^{1}$ \\ ${ }^{1}$ Universidade Vale do Rio Verde (UninCor), Avenida Castelo Branco 82, Chácara das Rosas, 37410-000, Três Corações, MG, Brazil \\ ${ }^{2}$ Faculdade de Odontologia de Ribeirão Preto (FORP/USP), Ribeirão Preto, SP, Brazil
}

Correspondence should be addressed to Matheus Henrique Lopes Dominguete; matheusdominguete@ig.com.br

Received 5 October 2014; Accepted 9 November 2014; Published 23 November 2014

Academic Editor: Daniel Torrés-Lagares

Copyright (C) 2014 Matheus Henrique Lopes Dominguete et al. This is an open access article distributed under the Creative Commons Attribution License, which permits unrestricted use, distribution, and reproduction in any medium, provided the original work is properly cited.

Central ossifying fibroma is a benign slow-growing tumor of mesenchymal origin and it tends to occur in the second and third decades of life, with predilection for women and for the mandibular premolar and molar areas. Clinically, it is a large asymptomatic tumor of aggressive appearance, with possible tooth displacement. Occasionally treated by curettage enucleation, this conservative surgical excision is showing a recurrence rate extremely low. The objective of this study was to report a case of a 44-year-old woman, presenting a very large ossifying fibroma in the mandible, which was successfully treated with curettage, and to conduct a brief literature review of this lesion, focusing on the histology, clinical behavior, and management of these uncommon lesions.

\section{Introduction}

Central ossifying fibroma (COF) is the most common benign fibroosseous neoplasm of the oral and maxillofacial region. It was described by Menzel in 1872 but was appointed by Montgomery in 1927 [1]. This lesion tends to occur in the second and third decades of life, commonly in women, and in the mandibular premolar and molar areas [1-8].

Central ossifying fibroma usually presents clinically as a painless and expansive spherical or ovoid jawbone mass that may displace the roots of adjacent teeth and cause root resorption $[9,10]$. COF demonstrates either completely radiolucent or a mixture of radiolucent and radiopaque appearance (depending on the amount of internal calcification) $[10,11]$, and it is histologically composed of proliferating fibroblasts and osseous products that include bone and cementum-like material. However, there are some other lesions of the maxillary bones that should be included in the differential diagnosis, such as focal cementum-osseous dysplasia, osteoid osteoma, and fibrous dysplasia [12, 13]. Most COFs have a good prognosis and can be treated by conservative surgical excision through the use of curettage, enucleation, or excision $[1,2,11,12]$.

The aims of this report are to present a case of $\mathrm{COF}$ in the mandible and to provide a critical review of the current literature regarding lesions of this type.

\section{Case Report}

A 44-year-old black woman was referred to the maxillofacial surgery clinic of the Vale do Rio Verde University for evaluation of an asymptomatic swelling in the vestibular region of the left mandible canine (Figure 1). The exact date when the swelling was observed was not known. The overlying mucosa was normal in color, and the needle aspiration yielded negative results. In addition, no lymphadenopathy was found on the extraoral examination. Analysis of the panoramic radiograph revealed a lesion with a mixed radiopaque and radiolucent appearance, a well-circumscribed border from the right lateral incisor to the left second molar region, and a diameter of approximately $10 \mathrm{~cm}$ (Figure 2). There was 
TABLE 1: Characteristics of the cases treated by curettage reported in the literature.

\begin{tabular}{|c|c|c|c|c|c|}
\hline Case & Author & Genre/age & Location & Treatment & Follow-up \\
\hline 1 & Liu et al. [2] & $\mathrm{F} / 45$ & Left mandible & Curettage & \\
\hline 2 & Liu et al. [2] & $\mathrm{M} / 15$ & Right mandible & Curettage & \\
\hline 3 & Bertolini et al. [14] & $\mathrm{F} / 37$ & Left mandible & Curettage & \\
\hline 4 & Triantafillidou et al. [15] & $\mathrm{M} / 28$ & Right mandible & Curettage & Recurrence after 2 years \\
\hline 5 & Triantafillidou et al. [15] & $\mathrm{F} / 7$ & Right maxilla & Curettage & Recurrence after 6 months \\
\hline 6 & Triantafillidou et al. [15] & $\mathrm{F} / 16$ & Right mandible & Curettage & 17 years free of recurrence \\
\hline 7 & Triantafillidou et al. [15] & $\mathrm{F} / 14$ & Left mandible & Curettage & 17 years free of recurrence \\
\hline 8 & Triantafillidou et al. [15] & $\mathrm{M} / 54$ & Right mandible & Curettage & 11 years free of recurrence \\
\hline 9 & Triantafillidou et al. [15] & $\mathrm{F} / 41$ & Right mandible & Curettage & 9 years free of recurrence \\
\hline 10 & Triantafillidou et al. [15] & $\mathrm{F} / 43$ & Right mandible & Curettage & 4 years free of recurrence \\
\hline 11 & Triantafillidou et al. [15] & $\mathrm{F} / 37$ & Right mandible & Curettage & 3 years free of recurrence \\
\hline 12 & Triantafillidou et al. [15] & $\mathrm{M} / 55$ & Right mandible & Curettage & 2 years free of recurrence \\
\hline
\end{tabular}

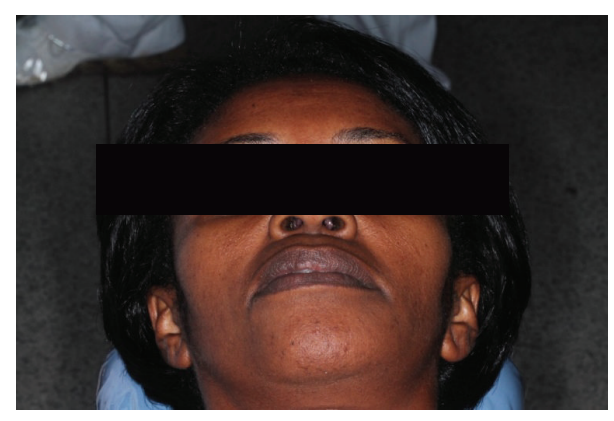

FIGURE 1: Preoperative clinical appearance of the patient.

radicular resorption of tooth 41. An incisional biopsy of the lesion was performed, and, based on the clinical findings, imaging results, and histopathologic features, a diagnosis of COF was confirmed. Under local anesthesia, a curettage enucleation of the tumor was performed, combined with the extraction of odontogenic remnants. The removed tumor was then sent again for histopathologic study, and the results confirmed the original diagnosis (Figures 7 and 8). After a twelve-month follow-up, no recurrence of this lesion was observed in this patient (Figure 9).

\section{Discussion}

COF is more frequent in female patients in the second to fourth decades of life $[3,10,16-18]$. Reports on where these tumors are most frequently localized differ, with some identifying the maxilla as the most frequent site $[5,13]$. However, the most commonly reported site is the mandible, especially in the molar region [9], as was observed in the present case.

Most cases of COFs are asymptomatic, with the first clinical manifestation being a swelling of the mandibular cortical layer, which produces a marked extraoral facial asymmetry $[9,10]$. The case presented herein showed clinical features similar to those of previously reported cases.

When the lesion occurs in patients between 5 years and 15 years of age, it is called a juvenile ossifying fibroma [19],

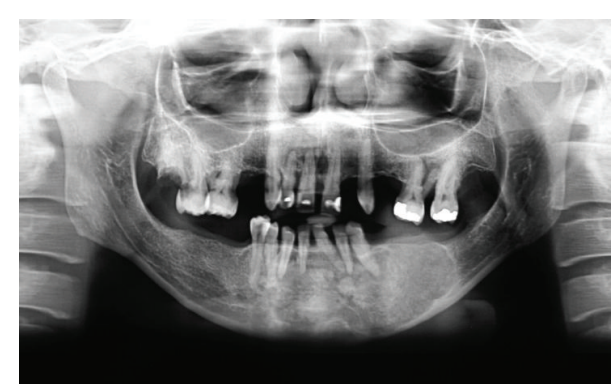

FIGURE 2: Panoramic radiograph indicates the left mandibular multilocular radiolucent lesion.

which differs from the reported case, because the patient is in the fourth decade of life, and shows the central variant of the central ossifying fibroma.

The differential diagnosis of COF is based on radiographic features. As a completely radiolucent lesion, COF can be misdiagnosed as a lesion with a radiographically similar appearance, such as focal cementoosseous dysplasia, odontogenic cyst, periapical granuloma, traumatic bone cyst, unilocular ameloblastoma, and central giant cell granuloma. The imaging features in the present case were similar to those of most reported cases, showing a circumscribed radiolucent lesion with well-defined margins and intralesional calcification $[7,9]$.

Histologically, COFs contain ossicles that connect to form bone trabeculae that are usually surrounded by osteoblasts and occasionally by osteoclasts. Cementum-like rounded calcifications are also frequently observed, and a mixture of these two types of calcifications is commonly observed inside a single lesion (Figure 5) [1, 2, 20, 21].

Enucleation by curettage has been reported as a method for the treatment of COF (Table 1). In some reports, the authors favor conservative surgery rather than en bloc resection. In these cases, conservative curettage is completed until healthy bony margins are reached $[20,21]$. Some cases treated by conservative surgical excision have shown no recurrence over a 17-year follow-up period [15]. In contrast, Zama et al. (2004) reported an immediate recurrence 15 days after 


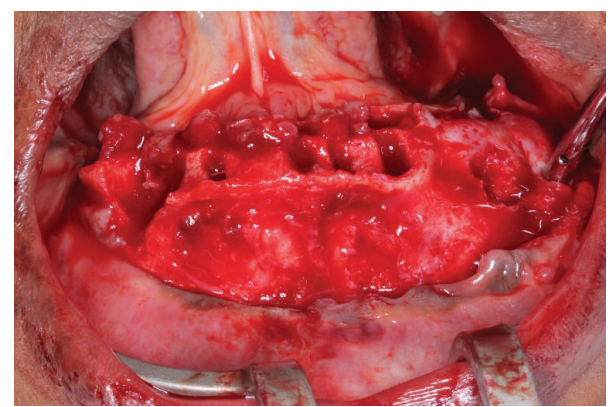

FIGURE 3: Surgical access to the injured area and the removal of all lower teeth.

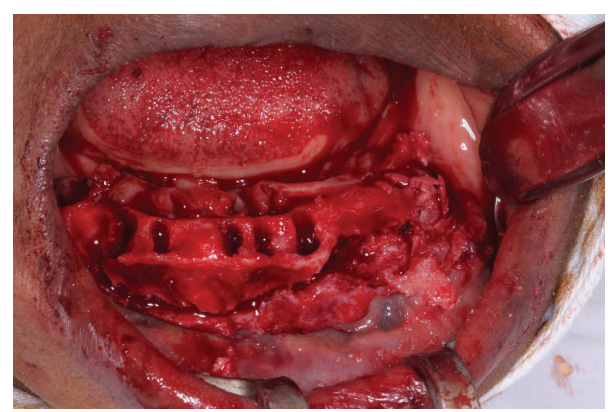

FIgURE 4: Removal of the lesion by enucleation with curettage.

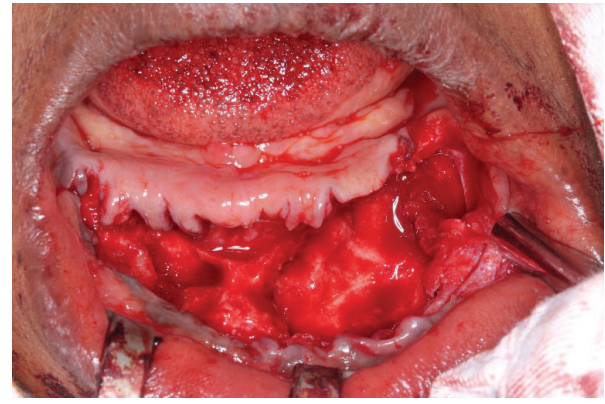

FIGURE 5: Surgical site after removal of the entire lesion.

conservative surgery to treat COF of the mandible, which required a second operation for hemimandibulectomy and reconstruction [21].

The clinical management of COF remains uncertain. To avoid or minimize the chance of recurrence, a partial or en bloc resection of the jaw is preferred for larger lesions $[17,22]$. Although our reported case had a large lesion, the surgical protocol applied was conservative because the lesion was well circumscribed and could be separated from normal bone during surgery, and the current follow-up has not shown any clinical signs of recurrence.

Our findings showed that the conservative surgical excision of COF appears to be a versatile, secure, and satisfactory treatment option (Figures 3 and 4). Although the recurrence rate of this tumor appears to be extremely low, patients must be followed carefully, particularly because the tumor

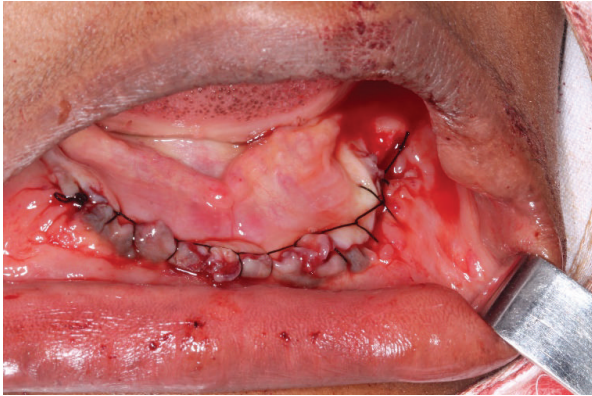

FIGURE 6: Suturing of the surgical site.

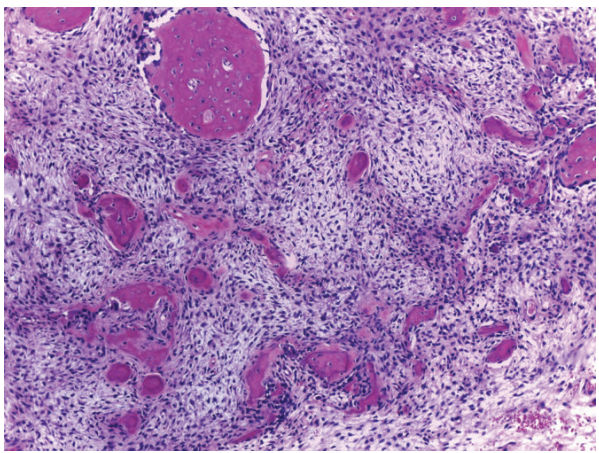

Figure 7: Histopathologic appearance of the ossifying fibroma showing fibroblastic stroma with small calcifications (hematoxylineosin, 10x).

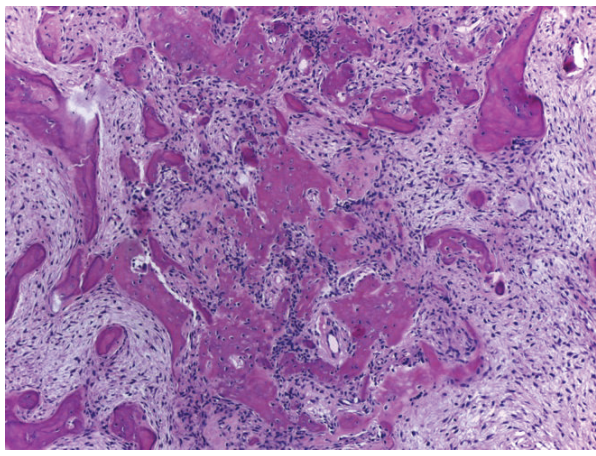

FIGURE 8: Histopathologic appearance of a central ossifying fibroma shows spherules of cementoid material in a highly cellular fibrous connective tissue stroma (hematoxylin-eosin, 10x).

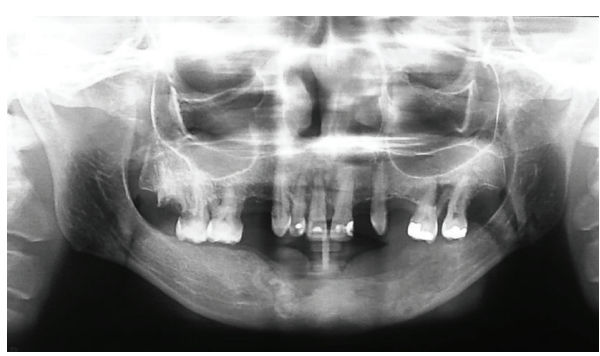

FIgURE 9: Panoramic radiograph 12 months after the surgery. 
has proved to be aggressive and to occasionally recur after conservative surgical procedures (Figure 6).

\section{Conflict of Interests}

The authors declare that there is no conflict of interests regarding the publication of this paper.

\section{References}

[1] A. H. Montgomery, "Ossifying fibromas of the jaws," Archives of Surgery, vol. 15, article 30, 1927.

[2] Y. Liu, H. Wang, M. You et al., "Ossifying fibromas of the jaw bone: 20 cases," Dentomaxillo Facial Radiology, vol. 39, no. 1, pp. 57-63, 2010.

[3] K. Matsuzaka, M. Shimono, T. Uchiyama, H. Noma, and T. Inoue, "Lesions related to the formation of bone, cartilage or cementum arising in the oral area: a statistical study and review of the literature," The Bulletin of Tokyo Dental College, vol. 43, no. 3, pp. 173-180, 2002.

[4] P. J. Slootweg, "Lesions of the jaws," Histopathology, vol. 54, no. 4, pp. 401-418, 2009.

[5] P. J. Slootweg and S. K. El Mofty, "Ossfying fibroma," in Pathology and Genetics Head and Neck Tumors, L. Barnes, J. W. Eveson, P. Reichart, and D. Sidransky, Eds., pp. 319-320, IARC Press, Lyon, France, 2005.

[6] C. Delilbasi, M. Sencimen, and K. M. Okcu, "A large mass in the maxilla: clinical features and differential diagnosis," Pathology Diagnostic Challenge, vol. 75, no. 4, 2009.

[7] A. C. P. Ribeiro, R. Carlos, K. P. Díaz, A. F. Gouvea, and P. A. Vargas, "Bilateral central ossifying fibroma affecting the mandible: report of an uncommon case and critical review of the literature," Oral Surgery, Oral Medicine, Oral Pathology, Oral Radiology and Endodontology, vol. 111, no. 2, pp. e21-e26, 2011.

[8] S. K. Ozarslan, G. Kocer, O. Toptas, and T. Baykul, "Cementoossifying fibroma: case report," Süleyman Demirel Üniversitesi Diş Hekimliği Fakültesi Dergisi, vol. 2, pp. 71-76, 2010 (Turkish).

[9] C.-C. Chang, H.-Y. Hung, J. Y. Chang et al., "Central ossifying fibroma: a clinicopathologic study of 28 cases," Journal of the Formosan Medical Association, vol. 107, no. 4, pp. 288-294, 2008.

[10] C. Toro, W. Millesi, N. Zerman, M. Robiony, and M. Politi, "A case of aggressive ossifying fibroma with massive involvement of the mandible: differential diagnosis and management options," International Journal of Pediatric Otorhinolaryngology Extra, vol. 1, no. 2, pp. 167-172, 2006.

[11] J. J. Sciubba and F. Younai, "Ossifying fibroma of the mandible and maxilla: Review of 18 cases," Journal of Oral Pathology and Medicine, vol. 18, no. 6, pp. 315-321, 1989.

[12] A. J. S. Pinos, M. V. O. Gaya, E. P. Sánchez, and V. Capilla, "Fibroma óseo juvenil: a propósito de un caso clínico," Medicina Oral, Patología Oral y Cirugía Bucal, vol. 9, no. 1, pp. 454-458, 2003.

[13] R. B. Brannon and C. B. Fowler, "Benign fibro-osseous lesions: a review of current concepts," Advances in Anatomic Pathology, vol. 8, no. 3, pp. 126-143, 2001.

[14] F. Bertolini, L. Caradonna, B. Bianchi, and E. Sesenna, "Multiple ossifying fibromas of the jaws: a case report," Journal of Oral and Maxillofacial Surgery, vol. 60, no. 2, pp. 225-229, 2002.

[15] K. Triantafillidou, G. Venetis, G. Karakinaris, and F. Iordanidis, "Ossifying fibroma of the jaws: a clinical study of 14 cases and review of the literature," Oral Surgery, Oral Medicine, Oral Pathology and Oral Radiology, vol. 114, no. 2, pp. 193-199, 2012.

[16] M. A. Keefe, R. Martín-Granizo, A. Sanchez-Cuellar, and F. Falahat, "Cemento-ossifying fibroma of the upper gingivae," Otolaryngology: Head and Neck Surgery, vol. 122, no. 5, p. 775, 2000.

[17] M. Gurol, S. Uckan, N. Guler, and P. Isil Yatmaz, "Surgical and reconstructive treatment of a large ossifying fibroma of the mandible in a retrognathic patient," Journal of Oral and Maxillofacial Surgery, vol. 59, no. 9, pp. 1097-1100, 2001.

[18] R. E. Marx and D. Stern, Oral and Maxillofacial Pathology. A Rationale for Diagnosis and Treatment, Quintessence, Chicago, IL, USA, 2002.

[19] S. Tortorici, M. L. Buzzanca, F. Burruano, and P. Difalco, "Juvenile central ossifying fibroma of the mandible: a case report," Journal of Pediatric Surgery, vol. 45, no. 10, pp. e1-e4, 2010.

[20] K. Nakagawa, Y. Takasato, Y. Ito, K. Yamada, P. J. Derome, and S. J. Haines, "Ossifying fibroma involving the paranasal sinuses, orbit, and anterior cranial fossa: case report," Neurosurgery, vol. 36, no. 6, pp. 1192-1195, 1995.

[21] M. Zama, S. Gallo, L. Santecchia, E. Bertozzi, and C. De Stefano, "Juvenile active ossifying fibroma with massive involvement of the mandible," Plastic and Reconstructive Surgery, vol. 113, no. 3, pp. 970-974, 2004.

[22] K. L. Kreutziger and L. S. Weiss, "Cementifying fibroma: resection of recurrent mandibular lesion with microsurgical preservation of inferior alveolar nerve and immediate reconstruction," Southern Medical Journal, vol. 87, no. 6, pp. 653-658, 1994. 


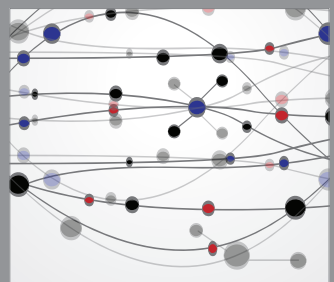

The Scientific World Journal
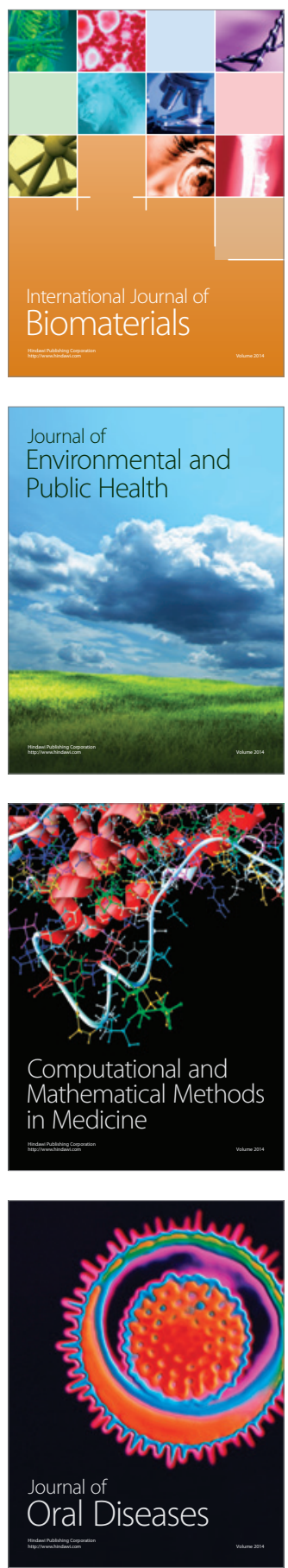
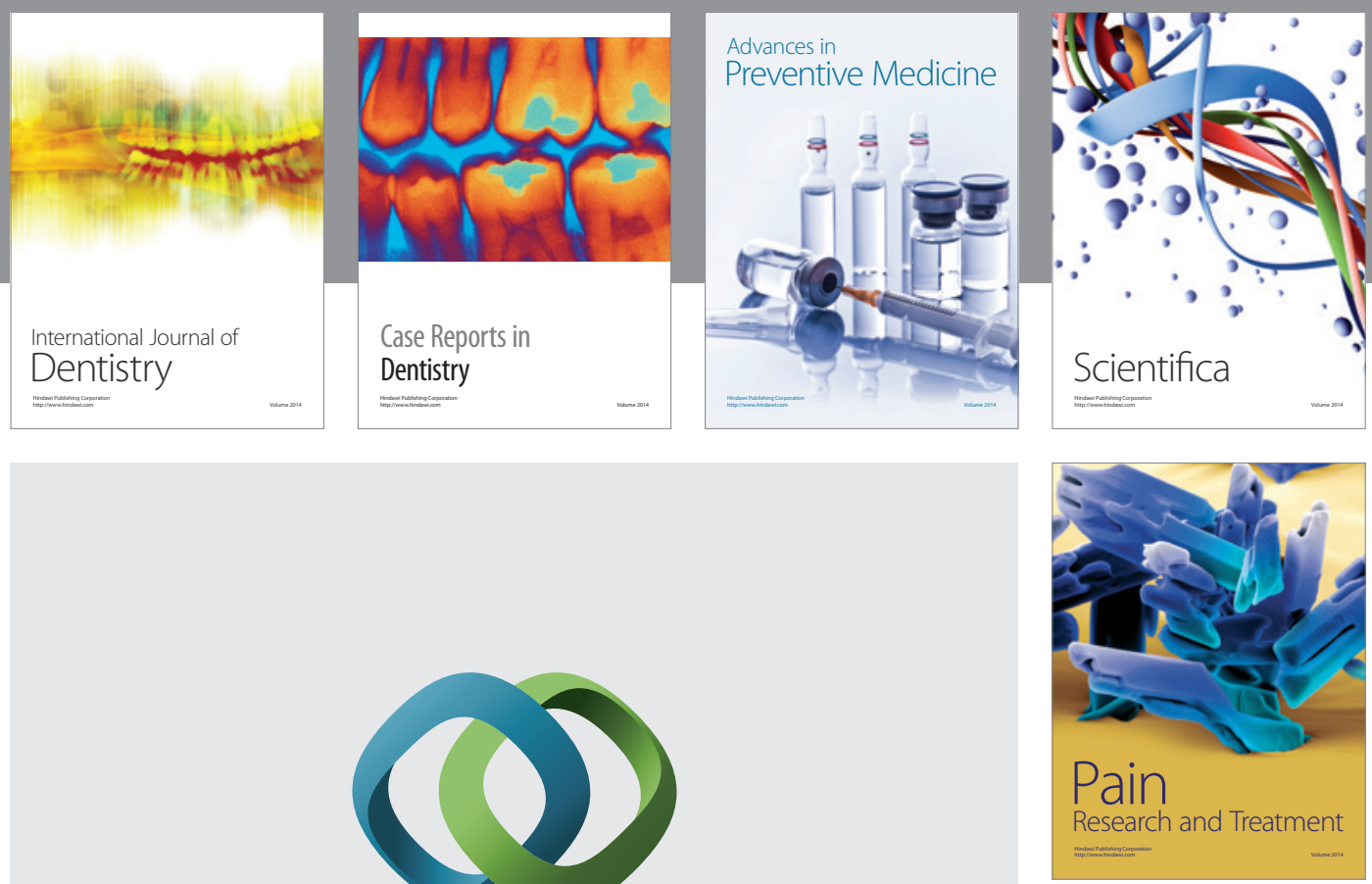

\section{Hindawi}

Submit your manuscripts at

http://www.hindawi.com
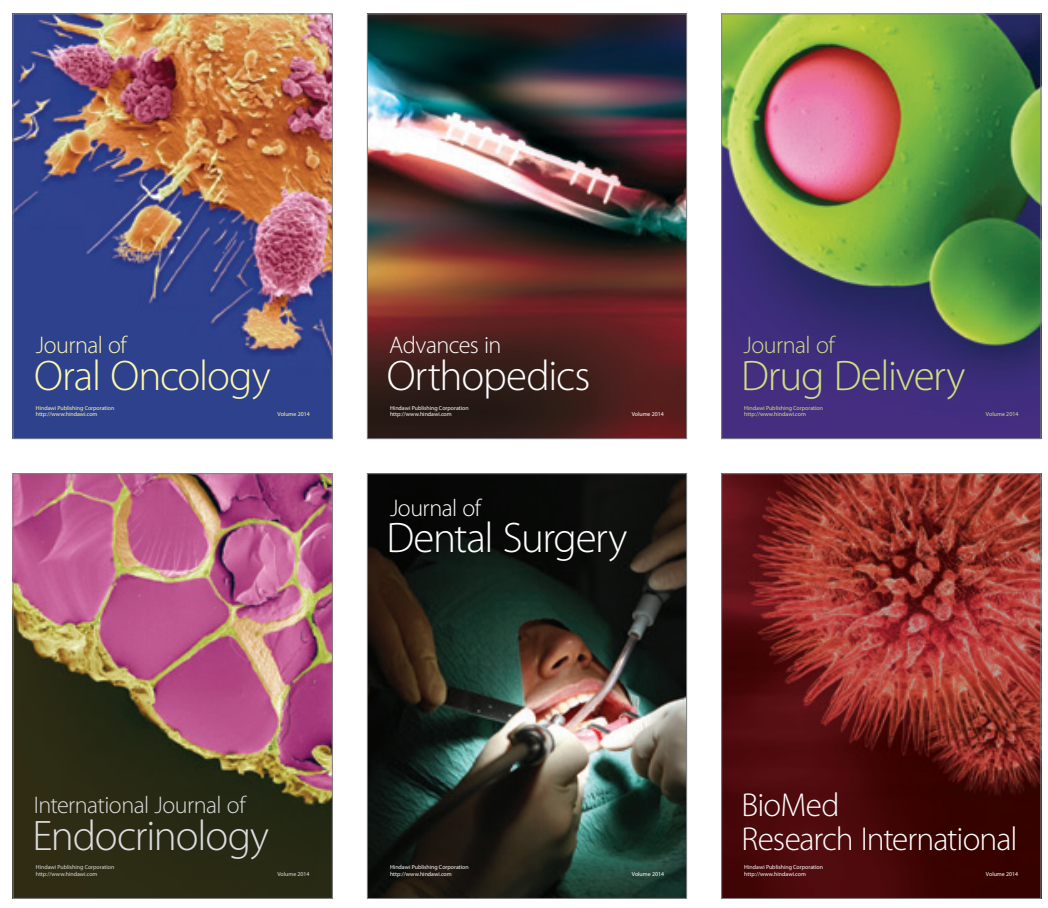

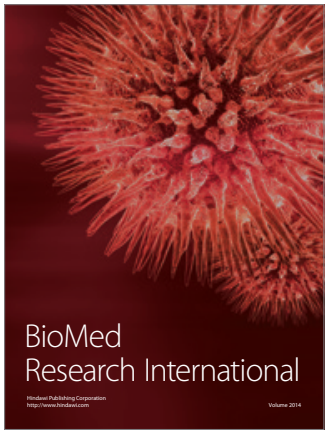

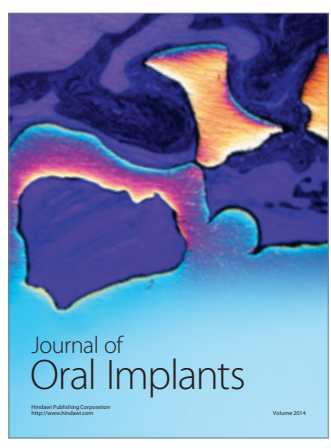
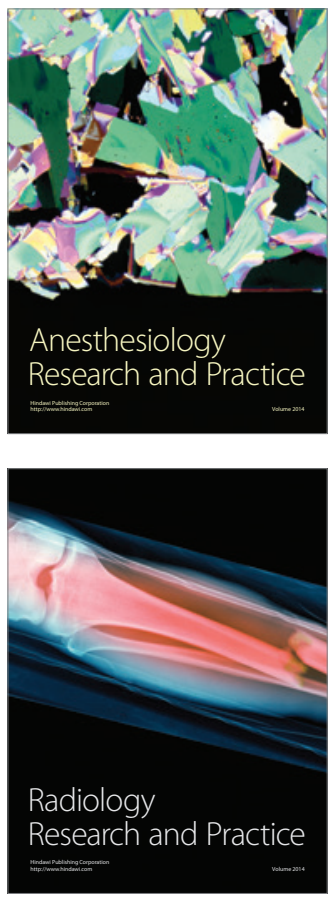